\title{
Investigation of a community outbreak of typhoid fever associated with drinking water
}

\author{
Amber Farooqui*, Adnan Khan and Shahana U Kazmi
}

\author{
Address: Immunology and Infectious Diseases Research Laboratory, Department of Microbiology, University of Karachi, Karachi, Pakistan \\ Email: Amber Farooqui* - amberfarooqui@hotmail.com; Adnan Khan - adnankh@uok.edu.pk; Shahana U Kazmi - shahana53@hotmail.com \\ * Corresponding author
}

Published: 20 December 2009

BMC Public Health 2009, 9:476 doi:10.1 186/147|-2458-9-476

This article is available from: http://www.biomedcentral.com/I47I-2458/9/476

(c) 2009 Farooqui et al; licensee BioMed Central Ltd.

This is an Open Access article distributed under the terms of the Creative Commons Attribution License (http://creativecommons.org/licenses/by/2.0), which permits unrestricted use, distribution, and reproduction in any medium, provided the original work is properly cited.
Received: 17 July 2009

Accepted: 20 December 2009

\begin{abstract}
Background: This report is about the investigation of an outbreak of typhoid fever claimed three human lives and left more than 300 people suffered within one week. The aim of this report is to draw the attention of global health community towards the areas that are still far from basic human essentialities.
\end{abstract}

Methods: A total of 250 suspected cases of typhoid fever were interviewed, out of which 100 were selected for sample collection on the basis of criteria included temperature $>38^{\circ} \mathrm{C}$ since the onset of outbreak, abdominal discomfort, diarrhea, vomiting and weakness. Food and water samples were also collected and analyzed microbiologically.

Results: Inhabitants of village lived in poor and unhygienic conditions with no proper water supply or sewage disposal facilities and other basic necessities of life. They consumed water from a nearby well which was the only available source of drinking water. Epidemiological evidences revealed the gross contamination of well with dead and decaying animal bodies, their fecal material and garbage. Microbiological analysis of household and well water samples revealed the presence of heavy bacterial load with an average total aerobic count $10^{6}-10^{9} \mathrm{CFU} / \mathrm{ml}$. A number of Gram positive and Gram negative bacteria including Escherichia coli, Klebsiella, Bacillus species, Staphylococcus species, Enterobacter species, and Pseudomonas aeruginosa were isolated. Lab investigations confirmed the presence of multidrug resistant strain of Salmonella enterica serovar Typhi in 100\% well water, 65\% household water samples and $2 \%$ food items. $22 \%$ of clinical stool samples were tested positive with Salmonella enterica serover Typhi

Conclusions: This study indicated the possible involvement of well water in outbreaks. In order to avoid such outbreaks in future, we contacted the local health authorities and urged them to immediately make arrangements for safe drinking water supply.

\section{Background}

Salmonella is most commonly involved bacteria in gastrointestinal tract infections. Its significant involvement in human mortality and morbidity is a major health con- cern. In 2006, The World Health Organization (WHO) estimated incidence of 16 to 33 million typhoid fever cases globally every year, with 500,000 to 600,000 deaths and case fatality rate of between 1.5 and $3.8 \%$ [1]. With 
more than $80 \%$ of global cases, South Asia is the most commonly reported region for the acquisition of typhoid fever since 1996 to 2005 [2]. The rate of incidence is 110 cases/100, 000 population [3]. There are several hospital based studies carried out in Pakistan that describe high incidence rate of typhoid fever in children [4,5]. However hospital based data does not reflect the actual disease status in normal community. Especially in remote areas where people live under low socioeconomic conditions and without basic necessities of life such as water, food, electricity and transport, incidence rate is much higher and often associated with small disease outbreaks.

Consumption of unsafe drinking water and inadequate sanitary conditions also contribute in increased rate of typhoid fever. In remote places, people usually rely on private and unsafe drinking water reservoirs for example ground wells are frequently found in these localities and act as only reservoir of drinking water without proper quality check [6]. According to an estimate in 2003, water borne infections claim 250,000 deaths each year in Pakistan among which typhoid fever is the leading cause [7].

In addition with high frequency and easy transmission, typhoid fever outbreaks also accompany with the threat of multidrug resistance. Multidrug-resistant (MDR) strains of Salmonella; resistant to chloramphenicol, ampicillin and trimethoprim are commonly observed since two decades and responsible for numerous outbreaks [8].

This study is based on the investigation of an outbreak of typhoid fever occurred in Nek Muhammad village, situated 25 kilometer far from metropolitan city of KarachiPakistan. Outbreak of typhoid fever claimed three human lives and left more than 300 people infected within one week.

\section{Methods}

\section{Epidemiological Description of Area}

Nek Muhammad village is a remote area situated 25 kilometer far from borders of metropolitan city of KarachiPakistan. The area is not well connected to the city due to less established means of communication. Approximately 500 poor people, mostly adults between age of 20-45 years and children under 12 years of age reside in this area with very limited facilities of water, food, electricity and health care. In October 2004, an outbreak of diarrhea and vomiting with high grade fever hit this area. Onset of symptoms was rapid and infected more than 300 people within 2 days. Local people contacted Edhi Foundationan NGO that immediately set up a medical camp to provide treatment and sent severe cases to local hospitals of Karachi. Due to severity of symptoms like over dehydration three people lost their lives within 5 days. In order to investigate the cause of outbreak, a team of microbiol- ogists and medical professionals from Immunology and Infectious Diseases Research Lab, Microbiology, KU visited the vicinity. We discovered a well in the locality which was polluted with dead and decaying bodies of birds and amphibians, their fecal material and garbage. The well was only source of drinking water. The villagers also informed us about their attempts to clean the well 2 days before the onset of symptoms. We interviewed the patients and collected various environmental and clinical samples with the help of Edhi Foundation. The investigation was approved by the Ethical Review Board of the University of Karachi, Pakistan.

\section{Sample collection and Inclusion Criteria}

We gathered information regarding their general health problems, onset of symptoms, daily activities, education status, age and eating habits through hypothesis generating interviews. A total of 250 people were interviewed. Due to small population size, we selected 100 patients for stool sample collection who belonged to different age groups and families and met the criteria of suspected typhoid fever. Inclusion criteria included temperature > $38^{\circ} \mathrm{C}$ since the onset of outbreak, abdominal discomfort, diarrhea, vomiting and weakness. Attack rate was also calculated on the basis of age. Due to unwillingness of healthy subjects to participate in investigation process, we were not able to conduct case control study. Stool samples were collected in clean plastic containers. A pea sized material from each sample was also transferred to CaryBlair transport medium. Samples were immediately transported to lab and processed within 2 hrs of collection.

A total of 10 water samples were collected from contaminated well using five different water collection buckets. Ninety well water samples, stored for different household purposes including cooking were also collected from different houses.

\section{Laboratory Investigation of Environmental Samples}

Quality assessment of water samples was performed by standard method [9]. Briefly, samples were processed to determine total aerobic bacterial count by standard Pour Plate technique. Presence of coliforms and Fecal E. coli was determined by Most Probable Number (MPN) and membrane filtration methods. In case of food items, 25 grams of each sample was weighed and transferred to sterile flask containing $100 \mathrm{ml}$ of phosphate buffer saline (PBS). Samples were homogenized under aseptic conditions. Three 10 -fold serial dilutions were prepared from homogenates to inoculate different culture media.

Media used for the detection of coliforms and Fecal E. coli included MacConkey's broth, 5\% sheep Blood agar, Nutrient agar, MacConkey's agar and Eosin Methylene Blue agar. Bile Echlin agar was used to check the presence 
of fecal Streptococci. In order to find out possible involvement of Salmonella, Shigella and Campylobacter, samples were inoculated on Salmonella Shigella (SS), Xylene lactose decarboxylase (XLD) and Campylobacter selective media.

\section{Lab Investigation of Clinical Samples}

Diarrheal stool samples were analyzed microscopically for the presence of ova and parasite(s). Bacteriological analysis was performed for the detection of Salmonella, Shigella, E. coli O157: H7, Yersinia, Vibrio cholerae using MacConkey's agar, SS agar, TCBS agar and Sorbitol MacConkey's agar (Oxoid). Briefly, half pea sized samples were inoculated on culture media plates and incubated aerobically at $37^{\circ} \mathrm{C}$ for 48 hours. Samples collected in transport swabs were used to inoculate Campylobacter selective medium supplemented with 5\% Sheep Blood followed by incubation under microaerophilic environment at $42^{\circ} \mathrm{C}$ for 48 to 72 hours. Transport swabs were further immersed in Selenite F broth (Oxoid).

Bacterial isolates from environmental and clinical samples were processed for identification using standard biochemical reactions such as oxidase, triple sugar iron, indole, sulfide, motility, citrate and urea hydrolysis. API20E strips (bioMerieux, Inc.) were used for further confirmation. Antibiotics susceptibility pattern was determined by standard methods [10]. Serotyping was performed to identify Salmonella strains using Specific antisera (BD).

\section{Results}

\section{Epidemiologic Investigation}

An outbreak of typhoid fever hit remote area of Nek village in October 2004 typically after 2 days of partial cleaning of reservoir well, the only source of drinking water in the village. Well cleaning was performed only by physical means. No chemical ingredient was used. The villagers did not share any common exposure or activity such as food and travel other than well water. Epidemiological analysis of food items indicated no statistical association with outbreak. Despite of cleaning attempt, the well was found to

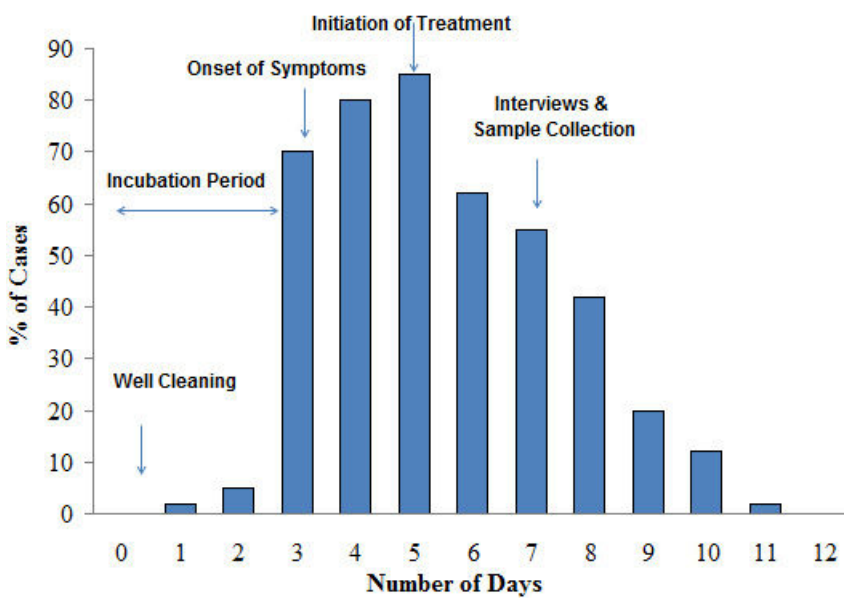

Figure I

Percent of typhoid patients showing symptoms during the outbreak. $(n=300)$

be polluted with dead and decaying bodies of birds, their fecal material and garbage which supported our suspicion regarding its involvement in disease outbreak. As shown in figure 1, symptoms started after 2 days of well cleaning which can be assumed as incubation period of the infection. Almost 300 people showed symptoms within 3 days post incubation period. In order to control the infection, $500 \mathrm{mg}$ of Ciprofloxacin was given per oral 12 hourly as antimicrobial regime. In case of children less than 12 years of age, $10 \mathrm{mg}$ of drug/ $\mathrm{kg}$ of body weight was given 12 hourly. Treatment was initiated with intravenous infusion in case of severely ill patients. Although, treatment measures were initiated after 2 days of disease onset, symptoms persisted for more than one week in most of individuals and claimed 3 human lives. Among the patients interviewed, 91\% reported fever, $65 \%$ diarrhea, $98 \%$ weakness, and $42 \%$ vomiting and other symptoms as listed in table 1. Analysis of attack rate indicated the involvement of different age groups ranged from 6 months to 60 years as shown in table 2 .

Table I: Clinical symptoms observed among residents*

\begin{tabular}{lll}
\hline Symptoms & Number of Residents (n) & Percentage (\%) \\
\hline Fever & 180 & 72 \\
Diarrhea & 163 & 65 \\
Vomiting & 107 & 42 \\
Abdominal cramps & 100 & 40 \\
Weakness & 245 & 98 \\
Nausea & 180 & 72 \\
Sore throat or cold & 63 & 25 \\
Stomach Discomfort & 205 & 82 \\
\hline
\end{tabular}

\footnotetext{
* includes only those individuals who were interviewed $(n=250)$
} 
Table 2: Involvement of different age groups in disease outbreak

\begin{tabular}{llll}
\hline Age* & Number of cases interviewed $(\mathbf{n})$ & Percentage $(\%)$ & Number of cases selected for sample collection \\
\hline$\leq 6$ months & II & 4.4 & 3 \\
up to 5 year & 14 & 5.6 & 5 \\
$5-12$ years & 30 & 12 & 14 \\
$13-25$ years & 35 & 14 & 15 \\
$26-45$ years & 115 & 46 & 39 \\
$46-60$ years & 24 & 9.6 & 9 \\
$\geq 60$ years & 20 & 8 & 15 \\
\hline
\end{tabular}

* includes only those individuals who were interviewed $(n=250)$

\section{Lab Investigation of Environmental samples}

Water samples tested positive for total coliforms and other fecal indicators. Total viable bacterial count ranged from $10^{6}-10^{9} \mathrm{CFU} / \mathrm{ml}$ of water which exceeded the standard limits of untreated potable water. Total viable count was predominantly constituted with coliform bacteria, however a number of other Gram positive and Gram negative organisms were also present in addition with normal environmental flora. Microbiological analysis revealed the presence of Salmonella enterica serovar Typhi in all well water samples while $65 \%$ of household stored water tested positive. The details are listed in table 3. Food items were loaded with environmental bacteria but no coliform was detected. Only 2\% samples tested positive for Salmonella Typhi. Figure 2 illustrates the presence of a variety of bacteria in water samples for example Escherichia coli. No O157:H7 serotype and other major gastrointestinal pathogens were observed. Other bacteria included Klebsiella isolated from $65 \%$ samples, Bacillus species (82\%), Staphylococcus species (45\%), Enterobacter species(64\%), Pseudomonas aeruginosa (85\%) and others.

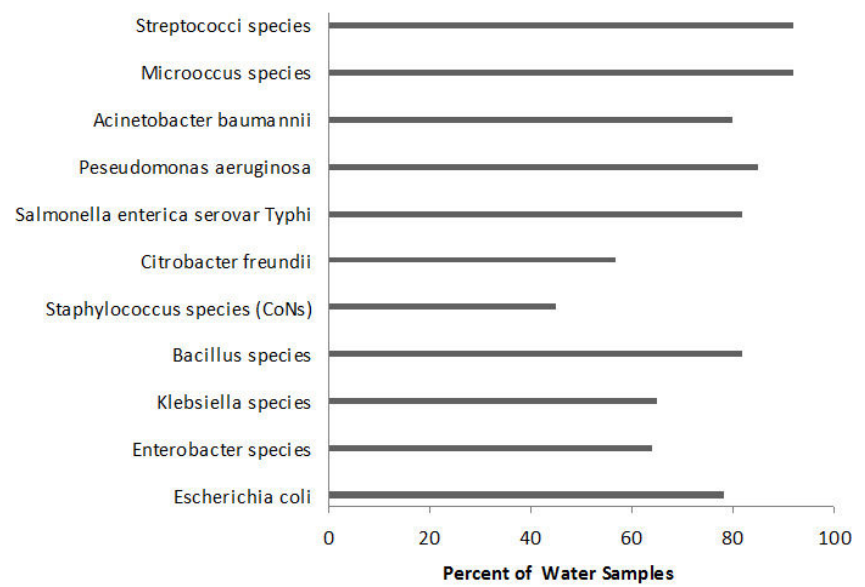

Figure 2

Rate of water samples being contaminated with various bacterial species. Samples $(n=100)$. CoNS = Coagulase negative Staphylococci
Salmonella enterica serovar Typhi strains were found to be resistant to first line therapeutic drugs i.e. ampicillin, chloramphenicol, co-trimoxazole/trimethoprim, however no ciprofloxacin and nalidixic acid resistance was observed. Other coliform bacteria were susceptible against a wide range of commonly used antibiotics including gentamicin, ciprofloxacin, imepenem, piperacillin/tazobactam, cefuroxime, and ceftriaxone. Ampicillin resistance was prevalent among $75 \%$ isolates.

\section{Lab Investigation of Clinical Samples}

Due to initiation of antibiotic treatment prior to sample collection, we decided to collect stool samples instead of blood culture to increase the chances of pathogen recovery. Moreover, majority of patients were not ready to participate in blood sample collection. Salmonella Typhi was isolated as sole pathogen from clinical samples. A total of 22 samples were found positive with MDR strains of Salmonella Typhi. However, the number of positive samples is under representing the actual number due to antibiotic treatment. Attack rate in different age groups was also calculated on the basis of bacteriological analysis as listed in Table 4. The data represents the recovery of organisms from every age group which is in agreement with symptoms observed. No other significant pathogen including Shigella, E. coli O157: H7, Yersinia, Vibrio cholerae and Campylobacter was isolated from stool samples. No evidence of protozoal and parasitic involvement was observed by microscopy.

\section{Discussion}

Drinking safe and healthy water is the right of every human being. Unsafe drinking water and inadequate sanitary conditions increase the risk of various public health hazards such as typhoid fever. On the basis of literature reviews and surveys, WHO estimates the involvement of diarrheal diseases in $39 \%$ of total water, sanitation and hygiene related disease burden worldwide. In Pakistan, $13.6 \%$ of total deaths are due to water sanitation and hygiene [11]. Disease magnitude is higher and unquantifiable in some remote areas where people usually rely on private water reservoirs like ground wells without any 
Table 3: Quality of clinical and environmental samples collected

\begin{tabular}{|c|c|c|c|c|c|}
\hline Samples & No. of samples (n) & $\begin{array}{l}\text { Average total viable } \\
\text { count* } \\
\text { (CFU/ml or g) }\end{array}$ & $\begin{array}{l}\text { Total coliform } \\
\text { Count } *^{\wedge}\end{array}$ & $\begin{array}{l}\text { Samples positive } \\
\text { for Salmonella Typhi } \\
(\%)\end{array}$ & $\begin{array}{l}\text { Samples positive } \\
\text { for fecal indicators\# } \\
(\%)\end{array}$ \\
\hline $\begin{array}{l}\text { Clinical Samples } \\
\text { (feces) }\end{array}$ & 100 & - & - & 22 & - \\
\hline Well water samples & 10 & $3 \times 10^{6}-1 \times 10^{7}$ & $\geq 1800$ & 100 & 100 \\
\hline $\begin{array}{l}\text { Household water } \\
\text { samples }\end{array}$ & 90 & $5 \times 10^{4}-4 \times 10^{7}$ & $\geq 1800$ & 72 & 65 \\
\hline $\begin{array}{l}\text { Cooked Food } \\
\text { samples }\end{array}$ & 50 & $2 \times 10^{3}-1 \times 10^{4}$ & 0 & 2 & 0 \\
\hline
\end{tabular}

$\mathrm{g}=$ gram, $\mathrm{CFU}=$ Colony forming unit, ${ }^{*}$ only for environmental samples, ^ was analyzed by MPN method, \# fecal indicators include fecal $E$. coli and Fecal Streptococci.

quality assessment. Most of the wells are not up to the mark of safe drinking water $[12,13]$ what we observed in Nek Muhammad village.

In this study, laboratory findings, clinical symptoms and epidemiological evidences link the presence of Salmonella enterica serovar Typhi in contaminated well water with illness. We were not able to perform DNA fingerprinting of Salmonella Typhi which was required to confirm bacteriological findings. Moreover, no genotypic characterization of $E$. coli and detection of viral pathogens were performed due to limited funds which can be considered as main limitations of our study.

The disease is not new for the region. There are several reports regarding the prevalence of Salmonella Typhi in different geographical locations of Pakistan $[4,5]$, and [14] for example in 1998, Luby et al reported the prevalence of typhoid in Karachi, resulted from high-dose exposures from multiple sources [15]. On the contrary the affected area in our study has never been reported for typhoid burden before. Involvement of MDR Salmonella Typhi strain is another health aspect to consider. Since two decades, MDR S. Typhi strains have been responsible for numerous outbreaks in several South Asian countries including Pakistan, India, and Bangladesh [8]. Rapid spread of MDR infection in small community like Nek Muhammad Village can provide a niche for the spread of antibiotic resistant strain among larger population.

Grossly contaminated and uncovered well, consumption of un-boiled water, poor sanitary and domestic hygiene conditions indicated the vulnerability of individuals. Moreover, inadequate well cleaning by local people disturbed the ecology of the natural source which increased the bio-load of well water and resulted in the addition of major diarrheal pathogens.

In order to prevent such outbreaks at global level, recently WHO introduced several household water interventions (HWST) including solar disinfection, bleach addition, boiling and use of low cost ceramic filters. The program not only benefits poor communities at individual level but will also lead to a benefit of up to US $\$ 60$ for every US $\$$ 1 invested [16]. Despite of large scale global efforts, situation cannot be easily controlled in rural areas like Nek Muhammad Village where majority of the inhabitants live in very poor economical conditions that doesn't allow them to boil or treat water. We, therefore advised them to at least filter the water through several layers of clean, fine

Table 4: Recovery of Salmonella enterica serovar Typhi from different age groups

\begin{tabular}{|c|c|c|}
\hline Age & No. of samples tested positive for Salmonella Typhi & Percentage* \\
\hline$\leq 6$ months & 1 & 33 \\
\hline up to 5 year & I & 20 \\
\hline $5-12$ years & 2 & 14 \\
\hline 13-25 years & 3 & 20 \\
\hline $26-45$ years & 13 & 33 \\
\hline $46-60$ years & 2 & 22 \\
\hline$\geq 60$ years & 0 & 0 \\
\hline
\end{tabular}

*Percentage is calculated on the basis of samples collected from respective group 
cotton clothe before drinking till the time they get proper arrangement. Later, a local NGO transported safe drinking water tankers to the vicinity. We also contacted local health authorities to immediately set up teams to visit the suburb and educate people about proper method of well cleaning as well as make arrangements for supplying safe drinking water. The incidence was publicized in media but no foreign health watchdogs were informed formally.

Pakistan is the country of growing geographical importance in these days. Provision of good quality life is not only better for the country but also important for the world community. Although, provision of quality education and poverty alleviation programs are government priorities, it is important to keep continuous vigilance in remote areas where people still live under inhumane conditions and provide them basic necessities of life. Reach and experience of local NGOs to such areas can be very helpful to bring up strong and sustained health reforms.

\section{Conclusions}

Our study presented the link of contaminated well water with the outbreak of typhoid fever in a remote village which claimed three human lives and left more than 300 people suffered within one week. In order to avoid such incidences in future, we contacted the local health authorities and urged them to immediately make arrangements for safe drinking water supply.

\section{Competing interests}

The authors declare that they have no competing interests.

\section{Authors' contributions}

AF: designed investigation parameters, conducted experiments, analyzed the data and wrote manuscript. AK: participated in study design, coordinated in interview process and carried out data analysis. SUK: provided material and bench space and supervised investigation process. All authors read and approved the final manuscript.

\section{Acknowledgements}

We would like to pay our sincere gratitude to Mr. Faisal Edhi and all team of Edhi Foundation-Pakistan who helped us to visit vicinity and managed to draw the attention of authorities and media with the intension of getting better living facilities for the villagers.

\section{References}

I. World Health Organization: Typhoid vaccine (Initiative for Vaccine Research). Geneva 2006 [http://www.who.int/ vaccine research/diseases/diarrhoeal/en/index7.html]. date accessed: $24 / 06 / 2009$

2. Health Protection Agency: Foreign travel-associated illness in England, Wales and Northern Ireland. 2007 [http:// www.hpa.org.uk/web/HPAwebFile/HPAweb C//204I86200928] date accessed: 26/06/2009

3. Crump JA, Luby SP, Mintz ED: The global burden of typhoid fever. Bull WHO 2004, 82:346-353.

4. Ahmad KA, Khan LH, Roshan B, Bhutta ZA: A 12 year clinical experience with paediatric salmonellosis from an endemic population in Karachi. Proceedings of The International Society for Infectious Diseases Meeting, Argentina 2000.

5. Bhutta ZA, Punjwani N, Lindblad BS: Concomitant bacteremia as a risk factor in diarrhoeal disease mortality: a case-control study of hospitalized children. Acta Paediatrica 1996, 85:809-8I3.

6. Barbara S, King W, Ley A, Hoey JR: A prospective study of rural drinking water quality and acute gastrointestinal illness. $B M C$ Public Health 200I, I:8.

7. Shah SM, Yousafzai M, Lakhani NB, Chotani RA, Nowshad G: Prevalence and correlates of diarrhea. Indian J Pediatrics 2003:207-2II.

8. Rowe B, Ward LR, Threlfall EJ: Multidrug-resistant Salmonella Typhi: a worldwide epidemic. Clin Infect Dis 1997, 24(Suppl I): 106-109.

9. World health Organization: From Microbial Impact. Guidelines for drinking water quality incorporating first addendum 2006:I I - I 43 [http:I /www.who.int/water sanitation health/dwq/gdwq0506.pdf]. date accessed II/06.2009

10. Manual of Clinical Microbiology 7th edition. Edited by: Murray PR, Baron EJ, Pfaller MA, Tenover FC, Yolken RH. American Society for Microbiology Press; 2005.

II. Prüss-Üstün A, Bos R, Gore F, Bartram J: Safer water Better health. World Health Organization report 2008 [http://www.who.int/ quantifying ehimpacts/publications/saferwater/en/index.html]. date accessed 29/06/2009

12. WWF-Pakistan: From Water and health related issues in Pakistan. Fresh water and toxic programme 2007:I-20.

13. Ali SM: From Poverty and child mortality in Pakistan. In In Micro Impact of Macroeconomic Adjustment Policies (MIMAP) Pakistan project report Pakistan Institute of Development Economics, Islamabad; $2001: 1-18$.

14. Siddiqui F], Rabbani F, Hasan R, Nizami SQ, Bhutta ZA: Typhoid fever in children: some epidemiological considerations from Karachi, Pakistan. International Journal of Infectious Diseases 2006, 10:215-222.

15. Luby SP, Faizan MK, Fisher-Hoch SP, Syed A, Mintz ED, Bhutta ZA, Mccormick JB: Risk Factors for Typhoid Fever an endemic Setting, Karachi, Pakistan. Epidemiology and Infection 1998, 120:129-138

16. World Health Organization: The International Network to Promote Household Water. Combating Waterborne Disease at \begin{tabular}{l} 
the Household Level. 2007 [http://www.who.int/ \\
\hline
\end{tabular} water sanitation health/publications/

combating diseasepart/lowres.pdf]. date accessed: 12/6/2009

\section{Pre-publication history}

The pre-publication history for this paper can be accessed here:

\section{http://www.biomedcentral.com/1471-2458/9/476/pre} pub

\section{Publish with Bio Med Central and every scientist can read your work free of charge}

"BioMed Central will be the most significant development for disseminating the results of biomedical research in our lifetime. " Sir Paul Nurse, Cancer Research UK

Your research papers will be:

- available free of charge to the entire biomedical community

- peer reviewed and published immediately upon acceptance

- cited in PubMed and archived on PubMed Central

- yours - you keep the copyright

Submit your manuscript here:

http://www.biomedcentral.com/info/publishing_adv.asp 